\title{
Comparing Student Performance in Online and Face-to-face Delivery Modalities
}

\author{
Jeffrey L. Helms \\ Department of Psychology \\ College of Humanities and Social Sciences \\ Kennesaw State University
}

\begin{abstract}
The purpose of the research was to compare student performance in an online or face-to-face (F2F) required Psychology course on three distinct sets of variables (i.e., pre-course, course, and post-course variables). Analyses revealed mixed significant and nonsignificant results. Students did not differ in terms of such variables as hours transferred to the university from prior schools, total hours earned toward their degrees, and number of hours currently attempted. However, online students had significantly lower grade point averages, missed significantly more grade opportunities, and were significantly more likely to fail the course compared to their F2F counterparts. These and other results are discussed in relation to potentially developing a different lens through which to view student performance in online courses.
\end{abstract}

\section{INTRODUCTION}

As online course offerings and programs continue to grow in higher education, it only makes sense to investigate aspects of the delivery modality. Over the last decade, research has begun in earnest to address these very issues [1]. Arguably the largest study to date was a meta-analysis conducted by the US Department of Education (USDOE). Some of the results from the meta-analysis [1] found that:

- Online students preformed "modestly better on average" compared to their traditional, face-toface (F2F) counterparts. (p. xiv)

- "Instruction combining online and face-to-face elements had a larger advantage relative to purely face-to-face instruction than did purely online instruction.” (p. xv)

- Differences in implementation of online courses did not affect learning outcomes. (p. xv)

- When the materials and other salient aspects of the course were varied considerably between the online and F2F version, the effect sizes found were larger. (p. xvi)

Among other things, findings from the USDOE report also suggest similar outcomes in blended and online modalities (p. xvi). Interestingly then, it appears that, if done "correctly," the online delivery modality can provide the same (or at least not significantly different) learning environment/opportunity as the F2F (traditional) modality.

In looking at the USDOE study [1], one of the requirements to be included in the meta-analysis was 
random assignment to online or F2F delivery modality. Quasi-experimental and cross-over designs were also allowed. On the face of it, this inclusion criterion resonated with methodological rigor. Students, however, were not assigned randomly to a delivery modality. Rather, the students made the choice. As a result, the findings are less generalizable since self-assignment was at play.

The initial thrust of the USDOE study [1] was focused on K-12 education. The study, however, was necessarily expanded to include higher education settings due to the dearth of K-12 studies. In fact, many of the findings from the report are based on these studies involving higher education settings. Some additional findings relevant to undergraduate education included:

- When compared to effect sizes found for K-12 students in the analyses, effect sizes for undergraduates (and other older learners) were significantly positive.

- Equivalence was seen in effectiveness for both medical subject matter (e.g., nursing) and other subject matter (e.g., social sciences).

- Effectiveness was relatively equal in newer and older studies included in the analyses.

- Although not significant in the findings, effect size for declarative knowledge did not appear as large as effect sizes for other learning outcomes as measured in other studies (e.g., procedural knowledge).

Unlike the studies included in the USDOE meta-analysis [1], some research has chosen to investigate variables within the online delivery modality. For example, Waschull [2] investigated the impact of selfdiscipline and motivation on success in online Psychology courses. She, not surprisingly, found selfdiscipline and motivation to be predictive of success in an online course. Willging and Johnson [3] researched persistence and drop-out rates in an online master's degree program. Brinthaupt [4] analyzed students' end-of-term perceptions of an online careers course. Suffice it to say there are many other studies that investigate single variables within the online delivery modality.

Some research has examined variability between delivery modalities (i.e., online and F2F). Elvers, Polzella, and Graetz [5] found no differences in procrastination in accessing course information, exam scores, or attitudes about the respective course (i.e., online or F2F). However, they did find a significant negative correlation for online students between procrastination and exam scores. The negative relationship was also found for procrastination and attitude about the online course. Other research [6] found that online students made better grades on exams compared to their F2F counterparts. No difference was noted for grades on assignments.

Waschull [7] studied attrition, performance, and evaluation in research on variability between delivery modalities. She noted among the findings that in the condition where students self-assigned either to an online or F2F section, online students were more likely to fail the course. Surprisingly, however, course evaluations from online students were not significantly differently than their F2F counterparts. For the researcher-assigned condition, students' performance and evaluation were not significantly different between the modalities. This finding certainly suggests some internal student attributes at play. Interestingly, attrition was not significantly different between the self-assigned and research-assigned conditions.

Further complicating the literature on the subject is that coverage of the variety of variables that are available to study is spotty. As seen in the above examples, it is not uncommon for researchers to address one or two variables, while overlooking others. It is true that all studies must narrow focus in order to address adequately the issues of most concern. In doing so, potentially important pieces may go unexplored. These unexplored pieces lend themselves to future studies and programs of research. It is difficult, however, to draw together the disparate studies given the variety of methods, participants, variables measured, etc. Many of the studies that are available are plagued by small sample sizes and problematic methodologies [1]. 


\section{STUDY BACKGROUND}

Relatively less research has been done directly comparing students in the traditional F2F delivery modality to students in the online delivery modality for specific courses. When this has been done, it often does not compare specific courses with the intent of keeping all else equal (e.g., same professor, same semester, same assignments). Additionally, little research has looked at differences in students that choose one modality over the other when both are available at the respective institution and offered by the same professor (thereby eliminating that potentially conflicting variable). This gap in particular provided the motivation for the present study where a comparison was done of students in an online version to students in a F2F version of an undergraduate psychology course. The impetus for the study also included knowledge that for the preceding semester, the end-of-course average grade for students in all online psychology courses at the university was 2.16 (based on the traditional 4-point grade point average, GPA, scale). This number stands in contrast to the end-of-course average grade for students in all face-to-face (F2F) psychology courses that same semester at the university (2.78). If the courses are generally the same in terms of variables like rigor, why is the outcome so disparate (at least in terms of GPA)? Are there pre-existing or other differences that might account for the different outcome? How does behavior within the course differ?

It is important to contextualize this information by noting that the university's entrance to the area of online education has been motivated by two interconnected situations. The first factor which spurred the growth of online course offerings and degree programs was space constraints. In short, the university's growth necessitated exploration of course delivery options beyond "brick and mortar" classrooms. The university simply did not have the space to accommodate the student body growth experienced in the first decade of this century. An equally important component which motivated growth into the online learning arena was the university's desire to increase access to higher education to more adequately serve the various constituencies of the state, especially those in the relatively large designated catchment area of the public university. As a result of these motivating factors, the psychology department began in earnest to deliver more of its coursework online beginning in 2008.

Within this context, this study examined the above research questions in order to understand the similarities and differences between students enrolled in a 16-week semester-long online and a F2F version of a required Careers in Psychology course. The first difference-a deviation from earlier studies in the field (e.g., those included in the USDOE meta-analysis) —is the large number of students $(n=96)$ participating in the study (58 online and 38 F2F). To add to the existing literature, students self-selected their own delivery modality. There was no random assignment. This procedure allowed for potential insight into understanding the differences between students who "freely" opt for each modality as opposed to understanding the modality itself. Furthermore and unlike previous research, a myriad of variables were selected from three distinct areas of the course. The areas included historical student variables identified as pre-course variables (e.g., cumulative GPA), present course variables (e.g., grades, communication/correspondence), and a post-course variable (i.e., course evaluation). Numerous statistical analyses were performed including comparisons of demographic data, performance characteristics (e.g., grades, communication rates, assignment submissions), and course evaluations. Student perceptions were limited to the course evaluations so that the comparisons would be more rigorous and less based on instructor perceptions or hindsight.

\section{METHOD}

\section{A. Participants}

Subsequent to IRB approval, consent was obtained from individuals in the author's F2F section and online section of the Careers in Psychology course for the semester. This course is a lower-division undergraduate course required of and limited to Psychology majors. As such, investment in the course 
(including the necessity of earning at least a ' $\mathrm{C}$ ' in the course for credit towards graduation) should be potentially substantial compared to electives and non-major courses.

Out of a possible 105 participants (66 online and 39 F2F), 96 students (58 online and 38 F2F) consented to participate. (Importantly, and as is customary, analyses were adjusted statistically when $n$-values erroneously impacted results.) The researcher collected data for most of the variables from university databases (i.e., transcripts) with the exception of the self-reported history component which asked students the number of online courses taken. The high participation rate $(91.43 \%)$ is likely due in part to the limited time required of the participant since he or she only had to give consent and answer one other question.

The mean age for online students was 24.36 ( $S D=5.53$ ), and the mean age for F2F students was 22.55 $(\mathrm{SD}=5.83)$. Although the mean age for the online students was slightly higher, it was not statistically significant $(\mathrm{p}>.05)$.

Consistent with previous research [8], the online course had a larger percentage of female students (87.9\%) compared to the F2F course (57.9\%). A Chi-square test for independence (with Yates Continuity Correction) indicated a significant association between sex and delivery modality, $\chi^{2}(1, n=96)=9.78, p$ $=.002$, phi $=-.34$.

In terms of residence, students in both delivery modalities lived off-campus. For F2F students, 81.6\% lived off campus. For online students, $94.8 \%$ lived off campus. Although student housing is available, it can only accommodate approximately $15 \%$ of the entire student body at the present time.

\section{B. Procedure}

Because of the different delivery modalities, great care was taken to eliminate as many differences between modalities as possible. For example, students in both modalities took tests and submitted assignments online via the university's learning management system (LMS, i.e., WebCT Vista). The same course announcements were delivered simultaneously to both sections via the LMS. Due dates and times were the same. Participants were from the same semester and used the same required textbook. Although in-person/in-class communication was obviously available to students in the F2F class (e.g., asking questions in the class during lecture), both sections had the same opportunities to email, communicate with peers via discussion post, and communicate with the instructor via discussion post. Directions and grading rubrics for the two assignments were exactly the same. The only difference between the sections was the availability of required discussion topics for the online course and an equal number of discussions/activities for the F2F section. Although these were part of the course grades for students in each respective section and were weighted equally in terms of assigned point values, they were eliminated from analyses due to the differences in activities. No other substantive differences were made other than delivery modality. The same lecture PowerPoints were used in both sections with the exception that F2F students did not have access to the PowerPoints outside of lecture where the online students had access to them online.

Data for the respective sections were gathered from students' online transcripts, the LMS for usage data and course grades/assignments, and a separate course evaluation system utilized by the university. Data were aggregated using SPSS and Microsoft Excel as appropriate.

\section{RESULTS}

Three sets of statistical analyses were conducted. The first set of analyses was done on the pre-course variables (i.e., those variables present before enrollment in the course). The second set of analyses was completed on the course variables (i.e., those variables gathered during the course). Lastly, the third set was conducted on a post-course variable (i.e., the course evaluation). Each set of analyses is taken in turn and presented separately. 


\section{A. Pre-Course Variables}

Using independent-samples $t$-tests, seven comparisons were made on the pre-course variables. Given the multiple comparisons, a more conservative alpha level was established using the Bonferroni adjustment. The more stringent alpha level used for these comparisons was $p<.007$.

\section{Transfer Hours}

As is the case at most institutions, students sometimes complete part of their degrees at other institutions before subsequently transferring to their current school. An independent-samples $t$-test was conducted to compare the number of transfer hours for students in the different sections. Students in the online course had transferred significantly more hours $(M=47.36, S D=30.96)$ compared to their F2F counterparts $(M$ $=19.58, S D=26.06 ; t(94)=4.57, p<.001$, two-tailed). The magnitude of the difference between the means (27.78, 95\% CI: 15.71, 39.86) was large (eta squared $=.18$ ).

\section{Total Semester Hours Earned To Date}

In terms of total semester hours earned, an independent-samples $t$-test revealed that the participants did not significantly differ in this regard with both having accumulated approximately 33 hours $(p=.98)$.

\section{Number of Online Courses Attempted}

Students were asked how many fully online courses they had attempted (including courses they were currently taking). Results from an independent-samples $t$-test indicate students in the online section attempted significantly more online courses $(M=3.81, S D=3.62)$ than students in the F2F section $(M=$ $1.05, S D=2.16 ; t(92.67)=4.65, p<.001$, two tailed). Eta squared indicated that the degree of the mean difference was large (mean difference $=2.76$; 95\% CI: 1.58 , 3.93; eta squared $=.19$ ).

\section{Number of Semester Hours Currently Attempted}

Given the potential impact on course outcome, an independent-samples $t$-test was conducted to compare the number of semester hours students were attempting for the semester. There was no significant difference between the hours attempted by students in the online section $(M=12.62, S D=3.31)$ versus the F2F $(M=12.97, S D=2.51)$ section $(p=.58)$. Eta squared indicated that the magnitude of the mean difference was extremely small (eta squared $=.003$ ).

\section{Grade Point Average (GPA)}

Cumulative GPA (CGPA) was retrieved for each participant (when available) and compared using independent-samples $t$-tests. Results show online students' CGPAs $(M=2.40, S D=.72)$ were significantly lower than their F2F counterparts $(M=3.05, S D=.61 ; t(78)=-4.26, p<.001$, two-tailed). When eta squared was calculated, the magnitude of the difference in the CGPA means was large (mean difference $=-.65$; 95\% CI: -.95 , -.35 ; eta squared $=.19$ ).

\section{Academic Standing}

Academic standing was assigned a numeric value from 1 to 3 whereby lower numbers indicated a better standing (i.e., $1=$ Good Standing, $2=$ Probation 1, $3=$ Probation 2). An independent-samples $t$-test revealed a non-significant difference between online $(M=1.24, S D=.52)$ and F2F students $(M=1.03, S D$ $=.17 ; t(56.73)=2.56, p=.013$, two-tailed). Eta squared results showed the magnitude of the mean difference as moderate (mean difference $=.21$; $95 \%$ CI: .05 , .38; eta squared $=.103$ ). Looking at this particular comparison from a different angle, 9 out of the 10 students who were not in "good standing" were enrolled in the online section of the course.

\section{Registration Time}

Time of registration for the course was also analyzed as a possible indicator of procrastination or priority setting (i.e., registering for a course closer to the cutoff date may suggest presence of procrastination or significant competing priorities preventing advanced planning). The number of days before the last possible day for course enrollment was calculated for each student. As a result, the higher the number, 
the earlier the student registered for the course. Results from an independent-samples $t$-test indicated that F2F students registered for the course significantly earlier $(M=114.16, S D=45.81)$ than online students $(M=39.86, S D=37.65 ; t(93)=-8.63, p<.001$, two-tailed). When eta squared was calculated, the magnitude of the difference in the means was very large (mean difference $=-74.30$; $95 \%$ CI: -91.39 , 57.21; eta squared $=.44$ ).

\section{B. Course Variables}

Using independent-samples $t$-tests and a Chi-square test, nine comparisons were made on the course variables. Given the multiple comparisons, a more conservative alpha level was established using the Bonferroni adjustment. The more stringent alpha level used for these comparisons was $p<.006$.

\section{Communication}

Three independent-samples $t$-tests were run in order to compare discussion posts to peers, question posts for the professor, and emails to the professor for online and F2F students. With the conservative $p<.006$ in mind, no significant differences between the delivery modalities were revealed. See Table 1.

\begin{tabular}{|l|l|l|l|l|l|}
\hline $\begin{array}{l}\text { Communication } \\
\text { Type }\end{array}$ & $\begin{array}{l}\text { Online } \\
\text { Mean }(S D)\end{array}$ & $\begin{array}{l}\text { Face-To-Face } \\
\text { Mean }(S D)\end{array}$ & $t(94)$ & $p$ & eta squared \\
\hline Posts to Peers & $.81(1.64)$ & $.29(.61)$ & $2.2^{*}$ & .031 & .06 (moderate) \\
\hline $\begin{array}{l}\text { Question Posts to } \\
\text { Professor }\end{array}$ & $.72(1.62)$ & $.61(1.65)$ & .35 & .728 & .001 (very small) \\
\hline Emails to Professor & $3.88(4.02)$ & $3.68(5.77)$ & .20 & .85 & .0004 (very small) \\
\hline
\end{tabular}

*Equal variances not assumed, $d f=78.34$

Table 1. Communication Patterns Based on Delivery Modality

\section{Accessing the Course Online}

Two independent-samples $t$-tests were run to compare the total number of online sessions spent and the total time spent online in the course for online and F2F students. With the noted Bonferroni correction in place, results show no significant difference between the total number of online sessions for students in the F2F section $(M=78.82, S D=32.96)$ and the students in the online section $(M=95.03, S D=57.34 ; t$ $(92.68)=1.76, p=.082$, two-tailed). Eta squared showed that the magnitude of the difference in the means was small (mean difference $=16.22$; $95 \%$ CI: -2.12 , 34.56; eta squared $=.03$ ).

Results for the total time spent online in the course was not significantly different for online students ( $M$ $=18 \mathrm{hr} 33 \mathrm{~min} 53 \mathrm{~s}, S D=10 \mathrm{hr} 54 \mathrm{~min} 35 \mathrm{~s})$ compared to their F2F counterparts $(M=13 \mathrm{hr} 24 \mathrm{~min} 11 \mathrm{~s}$, $S D=6 \mathrm{hr} 27 \mathrm{~min} 1 \mathrm{~s}$; t $(94)=2.63, p=.01$, two-tailed). Eta squared for this comparison revealed a moderate effect size for the difference in means (mean difference $=5$ hr $9 \min 42$ s; 95\% CI: 1 hr 15 min $44 \mathrm{~s}, 9 \mathrm{hr} 3 \mathrm{~min} 40 \mathrm{~s}$; eta squared = .07).

\section{Missing a Grade Opportunity}

Even given the same reminder announcements in the LMS, the same reminder emails to the sections, and the same due dates/times, a significant difference was found for missing a grade opportunity (i.e., missing/not submitting an assessment or assignment). A Chi-square test for independence (with Yates Continuity Correction) indicated a significant association between missing a grade opportunity and delivery modality, $\chi^{2}(1, n=91)=16.81, p<.001$, phi $=-.45$. In terms of the breakdown, $64.8 \%$ of the students in the online course missed at least one assessment or assignment whereas $18.9 \%$ of F2F students missed at least one assessment or assignment. 
Given the significant result and the medium-to-large effect size indicated by phi, additional analyses were performed to add clarity to this finding. The course included 9 assessments (8 tests and 1 final exam) and 2 assignments. Although F2F students missed an average of .27 assessments $(S D=.69)$, online students missed an average of .76 assessments $(S D=1.03, t(89)=2.53, \mathrm{p}=.013$, two-tailed). The magnitude of the difference between the means was moderate (mean difference $=.49 ; 95 \% \mathrm{CI}$. .11, .87; eta squared $=$ $.06)$.

A similar result was found for missed assignments. Online students missed an average of .27 assignments $(S D=.49)$, and the F2F students missed an average of .08 assignments $(S D=.28 ; t(87.81)=2.39, \mathrm{p}=$ .02 , two-tailed). The magnitude of this mean difference was moderate as well (mean difference $=.19$; $95 \%$ CI: .03, .35; eta squared $=.06$ ).

\section{Assignment and Assessment Grades}

Comparisons via independent-samples $t$-tests were also performed on the assessment and assignment grades. For analysis purposes, all 9 assessment grades were added to form one variable. The difference between the online $(M=181.77, S D=34.16)$ and the F2F $(M=194.95, S D=31.24)$ sections was not statistically significant $(t(89)=-1.87, p=.065$, two-tailed). An eta squared calculation revealed a mean difference magnitude in the small to moderate range (mean difference $=-13.18$; $95 \%$ CI: $-27.18, .82$; eta squared $=.04$ ).

A similar analysis was completed with the assignment grades whereby a new variable was calculated by adding together the points earned for each assignment. The difference between online $(M=48.31, S D=$ $20.25)$ and F2F $(M=61.41, S D=16.14)$ students was significant $(t(86.89)=-3.42, \mathrm{p}=.001$, two-tailed $)$. The magnitude of the difference between the means was moderate to large (mean difference $=-13.09$; 95\% CI: -20.69, -5.49; eta squared $=.12$ ).

\section{Final Course Grade}

Final letter grades for the course were converted to the standard GPA values (i.e., $A=4, B=3, C=2$, $D$ $=1, \mathrm{~F}=0$ ) for analysis purposes. Final letter grade distribution is provided in Table 2 for illustrative purposes. An independent-samples $t$-test provided corroboration for the comparisons of assignment and assessments grades noted earlier. The difference between online $(M=1.7, S D=1.25)$ and $\mathrm{F} 2 \mathrm{~F}(M=2.59$, $S D=1.24)$ was significant $(t(91)=-3.41, p=.001$, two-tailed). Eta squared calculations for the magnitude of the mean difference on these two variables were moderate to large (mean difference $=-.90$; $95 \%$ CI: -1.42 , -.38; eta squared $=.11$ ). Unsurprisingly, the final course grade for the respective delivery modality was positively correlated with the CGPA for the respective delivery modality (Online: $r=.421$, $n=43, p=.005 ;$ F2F: $r=.603, n=34, p<.0005$ ).

\begin{tabular}{|l|l|l|}
\hline Final Course Grade & Online & Face-To-Face \\
\hline A & $10.71 \%$ & $24.32 \%$ \\
\hline B & $14.29 \%$ & $37.84 \%$ \\
\hline C & $28.57 \%$ & $21.62 \%$ \\
\hline D & $26.79 \%$ & $5.41 \%$ \\
\hline F & $19.64 \%$ & $10.81 \%$ \\
\hline
\end{tabular}

Table 2. Percent of Students in the Respective Delivery Modality Earning a Particular Final Letter Grade

\section{Post-Course Variable}

\section{Course Evaluations}


A standard university-approved course evaluation is administered to all students at the end of their courses (regardless of delivery modality). Data are made available to instructors after final course grades are submitted. Although completion of the anonymous evaluation is voluntary, participation still ranged from 23 to 31 for the online students and 15 to 16 for F2F students depending on the question. Each of the 14 included questions was answered on a 4-point Likert-type scale with higher scores being more favorable. As noted in Table 3, means were well above Likert-value 3 for all questions. A series of 14 independent-samples $t$-tests compared the ratings for online and F2F students. Even without using the more conservative Bonferroni correction for the alpha level $(p<.004)$ given the number of tests, no significant differences were found for any of the questions.

\begin{tabular}{|c|c|c|c|c|}
\hline Item & Modality & $n$ & $M$ & SD \\
\hline \multirow{2}{*}{$\begin{array}{l}\text { 1. The instructor is knowledgeable about } \\
\text { the course material. }\end{array}$} & Online & 30 & 3.63 & 67 \\
\hline & F2F & 16 & 3.81 & .40 \\
\hline \multirow{2}{*}{$\begin{array}{l}\text { 2. The instructor has an effective style of } \\
\text { presentation. }\end{array}$} & Online & 28 & 3.21 & 1.00 \\
\hline & $\mathrm{F} 2 \mathrm{~F}$ & 16 & 3.50 & .63 \\
\hline \multirow{2}{*}{$\begin{array}{l}\text { 3. } \\
\text { The instructor } \\
\text { consultation. }\end{array}$} & Online & 28 & 3.29 & .98 \\
\hline & F2F & 15 & 3.47 & .52 \\
\hline \multirow[t]{2}{*}{ 4. The instructor challenges me to think. } & Online & 30 & 3.30 & 92 \\
\hline & F2F & 16 & 3.25 & 86 \\
\hline \multirow{2}{*}{$\begin{array}{l}\text { 5. The instructor treats students with } \\
\text { respect. }\end{array}$} & Online & 29 & 3.21 & 1.01 \\
\hline & $\mathrm{F} 2 \mathrm{~F}$ & 15 & 3.40 & .63 \\
\hline \multirow{2}{*}{$\begin{array}{l}\text { 6. The instructor makes course objectives } \\
\text { clear. }\end{array}$} & Online & 31 & 3.29 & 97 \\
\hline & F2F & 16 & 3.56 & .63 \\
\hline \multirow{2}{*}{$\begin{array}{l}\text { 7. The instructor effectively } \\
\text { technology to facilitate learning. }\end{array}$} & Online & 31 & 3.48 & .77 \\
\hline & F2F & 16 & 3.50 & 63 \\
\hline \multirow{2}{*}{$\begin{array}{ll}\text { 8. The instructor is enthusiastic abou } \\
\text { teaching the course. }\end{array}$} & Online & 30 & 3.30 & .84 \\
\hline & F2F & 16 & 3.50 & .63 \\
\hline \multirow{2}{*}{$\begin{array}{l}\text { 9. The instructor provides useful feedback } \\
\text { on student work. }\end{array}$} & Online & 31 & 3.19 & 1.01 \\
\hline & F2F & 16 & 3.44 & .63 \\
\hline \multirow{2}{*}{$\begin{array}{l}\text { 10. The instructor provides timely feedback } \\
\text { on student work. }\end{array}$} & Online & 31 & 3.52 & .72 \\
\hline & F2F & 16 & 3.56 & .51 \\
\hline \multirow[t]{2}{*}{ 11. The instructor is prepared for class. } & Online & 27 & 3.63 & 69 \\
\hline & F2F & 16 & 3.56 & .51 \\
\hline \multirow{2}{*}{$\begin{array}{l}\text { 12. The instructor facilitates discussion } \\
\text { related to course content. }\end{array}$} & Online & 27 & 3.37 & .84 \\
\hline & F2F & 16 & 3.44 & .81 \\
\hline \multirow{2}{*}{$\begin{array}{l}\text { 13. The instructor clearly explains the } \\
\text { grading system. }\end{array}$} & Online & 30 & 3.40 & .97 \\
\hline & F2F & 16 & 3.50 & .73 \\
\hline \multirow{2}{*}{$\begin{array}{l}\text { 14. The instructor responds appropriately } \\
\text { when differing viewpoints are expressed } \\
\text { in class. }\end{array}$} & Online & 23 & 3.52 & .73 \\
\hline & F2F & 15 & 3.53 & .64 \\
\hline
\end{tabular}

Note. Each question is answered on a 4-point Likert-type scale where higher scores are more favorable.

Table 3. Course Evaluation Items Based on Delivery Modality 


\section{DISCUSSION}

Apparently, the bottom line is that the students choosing the online modality and their resulting performance are different from the students choosing the F2F modality and their resulting performance. This finding, of course, is not surprising, especially to those of us who teach in both modalities. However, understanding those differences along with the similarities may take some work. As a result, each set of variables is discussed in order and with the hope of shedding a little more light on the above results.

\section{A. Pre-Course Variables}

Students taking the course were of similar age (i.e., nonsignificant mean age difference) and residential status (i.e., living off campus). By course design, all students were also Psychology majors. F2F and online students in the course were not significantly different in terms of how far along they were in college (i.e., no significant difference in hours earned) or in the number of hours they were attempting in the semester under investigation. These data suggest not only similarity in these attributes but also potentially similar commitment to their respective educational pursuits (i.e., they are potentially progressing toward their degree at the same rate currently). This particular interpretation is important since there might be some academics who suggest less commitment to higher education by students who take coursework online. These data do not support that perspective.

Although they did not differ in the above-noted characteristics, they certainly differed in terms of other attributes. Students in the online section transferred significantly more hours and registered significantly later for the course. The transfer of significantly more hours suggests a history of need for flexibility in pursuing higher education and tenacity in their pursuit regardless of needing to switch colleges. Starting and finishing at the same institution appears less likely in this cohort. Registering significantly later for the course deserves additional attention since it may be surmised that online students were registering for the course because there were no openings in the F2F section. It is true that more "seats" were available in the online section and that the F2F section filled sooner. However, and importantly, the course is not a prerequisite to other courses. Students were free to delay taking the course until it was available in the delivery modality they wanted. Selection of the online modality was a true "choice" for the students. The course is offered every semester (including summer session) and in both of the delivery modalities studied. If "seat" availability was the root difference from which other differences sprang, other contradictory differences would not have been significant (e.g., history of attempting online courses). Furthermore, students continued to register for both formats throughout the registration periods including during the university's drop/add period (the period of time at the beginning of the semester for students to add/drop courses and adjust personal schedules). This difference suggests an element of procrastination may be at work for students who opt for the online modality. The difference, however, may also be viewed through a lens of competing priorities whereby course selection is delayed so that personal life circumstances can be better understood prior to choosing to take a course, which is certainly a desirable quality. This aspect may be particularly relevant for students who choose online coursework as part (or all) of their degree program.

Understanding these pre-course variable differences would not be complete or contextualized without also noting the significantly larger number of female students in online courses (including the current study). With women sometimes disproportionately providing more caretaking for family members (e.g., children and elderly parents) and having other work commitments in addition to these responsibilities, educational priorities might necessarily and understandably fall in terms of emphasis. As such, the priority of education likely vacillates throughout the duration of a semester thereby impacting performance in coursework. Understanding potential performance differences from this framework might actually produce a perspective by the instructor of greater accomplishment by the student given all of these 
competing demands, regardless of the final "score" in a course. Although a possible cliché at this point, multitasking may be more definitive of those choosing the online format.

The explanation of differences cannot be the lack of experience in online courses. In fact and as seen in the results, students in the online modality attempted significantly more online courses than their F2F counterparts. "Attempted" is an accurate description since it is unknown if such attempts resulted in course credit or a successful grade. Even so, it seems to reason that consistently unsuccessful attempts would result in a potential modification to the students' choices regarding the online delivery modality. For example, students often have the option to engage in a mixed or hybrid delivery modality at the university whereby they complete approximately half of a course online and half F2F. It is unknown if students in this sample have attempted this type of course and, if so, what their success rate was. Regardless, it is quite clear that outcome (in terms of grade) is different for these populations even though the opportunity to learn the same material is equivalent. Unfortunately, true equality of opportunity may not be present.

A basic academic variable certainly warrants highlighting at this point. Similar to the overall final course GPA for all Psychology online and F2F courses for the previous semester as noted in the introductory material, online students' CGPAs coming into the course were significantly lower than their F2F counterparts. The .65 CGPA difference is quite concerning. Additional concern is raised when it was found that $90 \%$ of students not in "good standing" academically were enrolled in the online section. Could it be that students who are less prepared academically gravitate to the online section? Could this gravitation be based on a (inaccurate) belief of lower rigor due to the delivery modality? Could individuals choosing this delivery modality prioritize education differently than their F2F counterparts? Unfortunately, these questions can't be answered with the results at hand. However, and importantly, it is as likely, if not more likely, that competing demands (e.g., family and work responsibilities) and competing needs (e.g. necessity of convenience and flexibility in scheduling due to other demands) may disproportionately impact online students.

\section{B. Course Variables}

It is difficult not to assume that "something" had to be different for the students in the different delivery modalities when looking at the results of this group of variables. With as many variables held constant as possible, differences still emerged in student performance. Of first interest though is something that was not different...but should have been? No significant differences were found in communication patterns. This finding is alarming given that students did not significantly differ in their use of emails to the professor or their use of a discussion area to ask the professor questions (e.g., about assignments). They also did not differ in their use of the discussion area devoted to peer interaction and questions. For the online section, these findings were surprising given that online interaction (via posts and email) is the primary (and almost exclusive) way of communicating with the professor or peers about the course. This is in contrast to students in the F2F section who have the opportunity to ask questions before, during, and after the in-person class meetings as well as in designated online areas. Importantly, the data did not suggest that either section heavily utilized online communication resources. In a sense, the students in the online section were arguably less connected to the course compared to the F2F students. Although not exactly quantifiable, but likely important, is the physical presence of the instructor in the classroom. These regular F2F interactions (which are consistent with the "traditional" university experience) provided an interpersonal and "real" connection that simply cannot be dismissed or equated with a virtual relationship between and among students and the professor. Although unable to support this assertion with data from the present study, the interpersonal connection may be even more important for students beginning a discipline (i.e., Psychology) that is arguably all about interpersonal connection.

Another similarity is also concerning. The sections did not differ in the amount of time spent online or in the number of discrete sessions online. Given that this was the only venue to get lecture material for students in the online section, we expected time spent online and student participation in discrete online sessions to be higher for students in the online modality. This suspicion, as noted, was not validated. 
There are at least two possibilities that might help explain this lack of expected difference. First, the Bonferroni adjustment led to one finding at the $p=.01$ level to be categorized as nonsignificant. Second, students may have downloaded materials and then read and studied offline which would in essence make the online activities (e.g., assignment submission and test completion) almost identical for the different sections. Regardless, the similarity between sections still may lend credence to the possibility that students in the online section prioritize their education (or at least prioritize this course) differently compared to their F2F colleagues. To reiterate an earlier point, the prioritization is often complicated disproportionately for online students due to other life demands that may preclude being "plugged in" for longer periods of time (e.g., family responsibilities, work demands).

Grades and submission of grade opportunities were significantly different between the two modalities. Before obtaining a grade, students obviously must first submit the item to be graded. Not submitting or completing grade opportunities is where a part of the problem appears to be in the online students' performance, at least in this sample. As a reminder, students in both formats were given the same instructions, reminders, and due dates. Both modalities submitted all assignments via the LMS and completed all assessments online. In short, the majority of online students (64.8\%) failed to complete/submit at least one grade opportunity. This is significantly more than their F2F counterparts (18.9\%). Overall, online students missed almost three times as many assessments and assignments. Again, could it be for students in the online section that attending college or taking this course is not as high of a priority compared to other "things?" These other priorities, as noted earlier, potentially range from greater work commitments to greater family responsibilities. The data unfortunately cannot help with understanding this piece. However, being a novice at online courses is very unlikely to be a factor given that these students had attempted almost four online courses on average.

In terms of graded assessments, while online students accumulated less points overall, students in both sections fared equally well. This finding is consistent with Waschull's [7] study of an introductory psychology course. However, the difference in grades on course assignments was significant. Online students fared much worse than their F2F peers. Given that a more sustained time commitment is required to complete assignments relative to an assessment (i.e., a test), this may again speak to the online students' ability to set aside sufficient time to complete these types of projects relative to other noneducational pursuits (e.g., family responsibilities and job commitments). Importantly, both formats were provided all directions for completion of the course assignments at the start of the course and were welcome (encouraged) to submit assignments at any point up to and including the due date.

Lastly, final course grades were significantly higher for students in the F2F section. Although the distribution of final letter grades was skewed toward the top for the F2F section, the opposite was true for the online section. The difference was not between getting an 'A' and getting a ' $C$;' the difference was between a mean that would make the course count toward their major and a mean that would require retaking the course. Approximately $46 \%$ of the online students in this study would have to retake the course for it to count toward the Psychology major compared to approximately $16 \%$ of F2F students. This finding is also consistent with Waschull's [7] — students in her online introductory course were more likely to fail compared to F2F students. This finding in and of itself warrants closer attention by the academy since some universities limit the number of attempts in a particular course. For a required course in a discipline, firm policies in these areas may force students out of a major when it is life circumstances and not ability that is affecting outcome. Majors with larger online course offerings may see decreases in their respective majors due to these rules. Importantly, these types of rules (i.e., limited course repeats, minimum GPA requirements) may be disproportionately affecting students who choose to take online courses due to other competing priorities in their lives (e.g., jobs and caregiving responsibilities). This effect may not be intended, but the impact may be the same (i.e., decreasing full access to higher education). 


\section{Post-Course Variable}

Given such significant differences, it only stands to reason that students' perceptions of the course might be significantly different as well (i.e., “I didn’t do well so I didn’t like the course.”). As noted in the results and consistent with Waschull's [7] findings, this reasoning is not accurate. Students self-reported perceptions of the course did not differ based on delivery modality. The fact that both rated the course quite high is equally interesting. Unfortunately, evaluation responses cannot be paired with the students' other variables (e.g., CGPA, course grade) since course evaluations are anonymous and administered via a separate university system. It is safe to say that, even with this limitation, the perceptions of the course were generally positive regardless of delivery modality.

\section{LIMITATIONS AND HOPES FOR FUTURE RESEARCH}

Generalizability of results is somewhat limited when it comes to other courses, especially in other disciplines. However, it would be unwise to dismiss them out of hand. Instead, caution in application/generalization is more likely the prudent path to take. Although it was cumbersome to incorporate this number of analyses and variables (which may be why most other studies limit the variables under investigation), more variables might lend additional clarity to the above results. For example, what are some of the other competing priorities in students' lives (e.g., hours worked, family responsibilities)? What caused students to choose the online/F2F section as opposed to the other delivery modality? Given that time management, time availability, and procrastination may be a component to at least one of the variables (i.e., missing assignments or assessments), measurement of these attributes along with comparisons of course behavior and outcome would likely be enlightening. It is suggested, however, that a different method be used than that described by Elvers, Polzella, and Graetz [5]. In their study, they investigated the potential online course opportunities to "cause" procrastination in students randomly assigned to online or F2F sections of an introductory psychology course. Instead, it might be more informative to look at students' preexisting levels of trait-based procrastination as a possible factor in self-selection of online or F2F delivery modalities. Lastly, perceptions of interpersonal connectedness to the professor may shed even more light on this area of study, particularly for psychology and other social sciences. Incorporating these additional variables will likely add to a better contextualization of the performance outcomes in the different delivery modalities. This area continues to be ripe for study.

\section{BRINGING IT TOGETHER}

While opportunities for student learning are equally present in both online and F2F modalities, student results and student outcomes (e.g., grades) may be quite different. As such it may be more fruitful to investigate student factors affecting course participation and results as opposed to the delivery modality itself. Importantly, the implications of the research may affect universities' marketing of online courses and programs since they would arguably be obliged to be more forthcoming regarding the outcome of students in online courses. Courses are not cheap, even at a public institution. When almost half of students enrolled in a course are not successful, reasons for such circumstances must be sought and addressed. It appears from the present research that inputs correlate highly with the outputs. Students coming into an online course are not necessarily the "average" student. Rather, they are quite possibly the students who may be juggling a multitude of demands as they progress toward their degrees. With many other competing priorities in place, the result may be a complicated struggle to put forth the minimum expected to attain credit for coursework.

The opportunity to learn and achieve is there. As such, it is by no means an indictment of the delivery modality. In fact, it is probably an accolade to the delivery modality since it allows the opportunity to deliver a course in as near an equivalent manner as possible. The population of students grasping the opportunity may not be accessing the opportunity in the most optimal circumstances. It appears that the increasing emphasis on making higher education available to all has also made it available to those individuals who may not be able to give it enough (sustained) priority to be successful even though the opportunity is there. 
So the question that undoubtedly remains is "what now?" Should only individuals who can "prove" that the course is a priority for them be allowed to enroll in online coursework? This question seems loaded and kneejerk in response as well as overly paternalistic since the population is an adult one. Might it not be better to understand that many of the students are different and will surely remain different in outcome? The opportunity to succeed is the same (or at least extremely similar). The question that may be more appropriate is how do we effectively convey to students that the online format might not be best for their particular situation? Might they want to focus on those other more pressing priorities so that when the time comes, their education can move up the priority ladder for sustained periods of time (e.g., the length of a semester/term)? Since this type of communication/advising is arguably part of our "job," the onus will likely be on us, the educators and administrators, to instigate these conversations.

As a result, we likely need to reconfigure or adjust our own self-imposed, traditionally-defined (and limiting) understanding of educational success. Maybe completion of a course (regardless of grade to some extent) is the goal for a proportion of students who find themselves in the online learning environment. The key will be to not drift downwards in terms of expectations given the different populations being served and to maintain consistent and appropriate standards to the subject matter. This piece may be harder to do given increasing demands by administration and the larger community (e.g., funding sources like state legislatures) to retain, progress, and graduate more students. Results from the present study support the position that the course delivery modality is not a problematic culprit, but rather, a modality serving a student population with potentially complicated and conflicting demands and goals. As such, we should be willing to address head-on these complications with the goal of continuing (and even increasing) access to higher education and improving individualized success rates.

\section{REFERENCES}

1. U.S. Department of Education; Office of Planning, Evaluation, and Policy Development; Policy and Program Studies Service. Evaluation of evidence-based practices in online learning: A meta-analysis and review of online learning studies (Contract No. CO-0040 Task 0006 with SRI International): 2010. http://www2.ed.gov/rschstat/eval/tech/evidence-based-practices/finalreport.pdf

2. Waschull, S. B. Predicting success in online psychology courses: Self-discipline and motivation. Teaching of Psychology 32: 189-192 (2005). http://top.sagepub.com/

3. Willging, P.A., \& Johnson, S. D. Factors that influence students' decision to dropout of online courses. Journal of Asynchronous Learning Networks 8(4): 105-118 (2004). http://sloanconsortium.org/publications/jaln main

4. Brinthaupt, T. M. Development and implementation of an online careers seminar in psychology. Teaching of Psychology 37: 58-62 (2010). doi:10.1080/00986280903425953

5. Elvers, G. C., Polzella, D. J., \& Graetz, K. Procrastination in online courses: Performance and attitudinal differences. Teaching of Psychology 30: 159-162 (2003). http://top.sagepub.com/

6. Poirier, C. R., \& Feldman, R. S. Teaching in cyberspace: Online versus traditional instruction using a waiting-list experimental design. Teaching of Psychology 31: 59-62 (2004). doi: 10.1207/s15328023top3101_11

7. Waschull, S. B. The online deliver of psychology courses: Attrition, performance, and evaluation. Teaching of Psychology 28: 143-147 (2001). http://top.sagepub.com/

8. Larson, D. K., \& Sung, C-H. Comparing student performance: Online versus blended versus faceto-face. Journal of Asynchronous Learning Networks 13(1): 31-42 (2009). http://sloanconsortium.org/publications/jaln_main 


\section{ABOUT THE AUTHOR}

Jeffrey L. Helms is Professor of Psychology at Kennesaw State University in Kennesaw, GA. In addition to his experience teaching at the undergraduate and graduate levels, he also is licensed as a psychologist and maintains a small consulting practice where, among other things, he provides academic coaching for pre-tenure and post-tenure academics.

\section{ACKNOWLEDGMENTS}

This research was supported in part by a grant from the Kennesaw State University Center for Excellence in Teaching in Learning. Jennifer Willard, Roxanne Donovan, and Amy Buddie are thanked for their assistance with the data analyses. 